\title{
Introduction to the Special Issue on Vietnamese
}

\author{
Andrew Simpson ${ }^{1}$
}

Published online: 30 October 2017

(C) Springer Science+Business Media B.V. 2017

\section{Introduction}

This Special Issue on Vietnamese grew out of the 9th International Workshop on Theoretical East Asian Linguistics (TEAL-9), held at the University of Nantes, France on September 25-26, 2014. Papers under review were those presented during the Special Vietnamese Syntax-Semantics Session of the workshop. We want to give special thanks to Lisa Cheng (University of Leiden) and Hamida Demirdache (University of Nantes), two of the workshop organizers, who proposed this special issue, as well as the authors for submitting their work to JEAL for review, and the many reviewers who helped shape the result.

Andrew Simpson

andrew.simpson@usc.edu

1 Los Angeles, CA, USA 